\title{
Acute Events that Lead to Cervical Disc Herniation Causing Radiculopathy- A Study in a Tertiary Care Centre in Eastern India
}

\author{
Ramesh Bhattacharya ${ }^{1}$, Shantanu Ghosh², Kartick Chandra Ghosh ${ }^{3}$, Sarbajit Das ${ }^{4}$, Suman Das ${ }^{5}$, Hem Krishna Pattem6, \\ Gouranga Prosad Mondal ${ }^{7}$
}

${ }^{1}$ Associate Professor, Department of Neurology, CNMC, Kolkata, West Bengal, India. ${ }^{2}$ Assistant Professor, Department of Neurosurgery, CNMC, Kolkata, West Bengal, India. ${ }^{3}$ Associate Professor, Department of Neurology, CNMC, Kolkata, West Bengal, India. ${ }^{4}$ Post Doctoral Trainee, Department of Neurology, CNMC, Kolkata, West Bengal, India. ${ }^{5}$ Post Doctoral Trainee, Department of Neurology, CNMC, Kolkata, West Bengal, India. ${ }^{6}$ Post Doctoral Trainee, Department of Neurology, CNMC, Kolkata, West Bengal, India. ${ }^{7}$ Professor, Department of Neurology, CNMC, Kolkata, West Bengal, India.

\section{ABSTRACT}

\section{BACKGROUND}

Cervical disc prolapse causing radiculopathy is one of the most common disorders treated by both neurologists and spine surgeons. Herniation of disc most commonly occurs in those below the age of 45 years. Pain appears in the neck and radiates towards the arms or vice versa i.e. arises in the arm and radiates to the neck. With aging and other risk factors, nucleus pulposus of cervical intervertebral disc show degeneration or dehydration. This disc may rupture through the posterior annulus fibrosus into the spinal canal or into the neural foramen compressing the exiting nerve root. Acute events can produce disc prolapse in those susceptible individuals who are already having degenerated disc.

\section{METHODS}

The study includes patients attending the OPD or those admitted in the Neurology and Neurosurgery Department of Calcutta National Medical College and Hospital with symptoms of cervical radiculopathy. The study period was from 01.03.2018 to 28.02.2019. Inclusion criteria of the study were radicular pain with or without sensory or motor signs with MRI evidence of root compression, electrophysiologic evidence of cervical radiculopathy when MRI was contraindicated or noncontributory and symptoms onset was within the last 3 months.

\section{RESULTS}

In this retrospective descriptive study, acute events noted within 48 hours that lead to cervical disc herniation are road traffic accidents in $27.9 \%$. of the cases, lifting heavy objects accounted for $16.1 \%$ of the cases, violence and assault accounted for $11.7 \%$ of the cases, fall accounted for $10.3 \%$ of the cases, repetitive strain accounted for $10.3 \%$ of cases, Sports \& recreation accounted for $7.3 \%$ of the cases, falling objects accounted for $4.4 \%$ of the cases and no obvious cause (idiopathic) accounted for $11.7 \%$ of the cases. $77.9 \%$ of the cases of cervical disc prolapse occurred in persons below 49 years of age. In this series, incidence of cervical disc prolapse was higher in males $69.1 \%$.

\section{CONCLUSIONS}

There is a need for increasing awareness among both the medical and general population about the acute events that can cause cervical disc herniation so that necessary precautions taken and lifestyle modifications be done to maintain cervical spine health.

\section{KEYWORDS}

Acute Events, Cervical Disc Herniation, Radiculopathy
Corresponding Author:

Dr. Shantanu Ghosh,

C/4/49, Kendriya Vihar,

Kolkata-700052,

West Bengal, India.

E-mail: shashwata_shantanu@yahoo.co.in

DOI: $10.14260 / j e m d s / 2019 / 621$

Financial or Other Competing Interests: None.

How to Cite This Article:

Bhattacharya R, Ghosh S, Ghosh KC, et al. Acute events that lead to cervical disc herniation causing radiculopathy- a study in a tertiary care centre in Eastern India. J. Evolution Med. Dent. Sci. 2019;8(37): 2861-2864, DOI:
Submission 21-06-2019,

Peer Review 28-08-2019,

Acceptance 04-09-2019,

Published 16-09-2019. 


\section{BACKGROUND}

The intervertebral disc which lies between two adjacent vertebrae contains a gel like substance in the centre called nucleus pulposus and the outer part is called annulus fibrosus which is made up of fibrocartilage and it keeps the gel contained. Cervical disc herniation can occur with or without degeneration of disc. Usually disc herniation occurs laterally producing radiculopathy but rarely it may occur centrally producing myelopathy. The risk of disc prolapse increases around the age of $40 \mathrm{~s}$ or $50 \mathrm{~s}$. The irritation produced by herniated disc may be due to compression or inflammation. Symptoms produced by cervical radiculopathy may be sudden in onset and the most common cause is disc prolapse. It is caused by trauma, but most commonly preceding events may often not be recognized. Herniation of disc most commonly occurs in those below 45 years of age. Pain in the neck with radiation towards the arm that increases on coughing, sneezing, straining at stool and other Valsalva manoeuvre are the characteristic features ${ }^{1}$. Disc herniation between two cervical vertebra produces root compression, like C4-C5, C5-C6, C6-C7 disc prolapse produces C5, C6 and C7 radiculopathy respectively. These are the roots most commonly affected by cervical radiculopathy as they have greatest mobility. ${ }^{1}$

\begin{tabular}{|c|c|c|c|}
\hline Root & Sensory Symptoms & Weakness & $\begin{array}{c}\text { Reflex } \\
\text { Abnormality }\end{array}$ \\
\hline C5 & $\begin{array}{c}\text { Pain paraesthesia \& Loss of } \\
\text { sensation over Shoulder }\end{array}$ & $\begin{array}{c}\text { Deltoid biceps } \\
\text { brachioradialis }\end{array}$ & biceps, supinator \\
\hline C6 & $\begin{array}{c}\text { Pain paraesthesia \& loss of } \\
\text { sensation over thumb or lateral } \\
\text { dorsal forearm }\end{array}$ & $\begin{array}{c}\text { Biceps Brachioradialis } \\
\text { Triceps }\end{array}$ & $\begin{array}{c}\text { biceps, } \\
\text { brachioradialis }\end{array}$ \\
\hline C7 & $\begin{array}{c}\text { above symptoms \& sign dorsal } \\
\text { ateral Forearm and hand \& Index } \\
\text { finger }\end{array}$ & Triceps \\
triceps and pronator & $\begin{array}{c}\text { above symptoms \& signs Medical } \\
\text { forearm hand and ring \& little } \\
\text { finger }\end{array}$ & $\begin{array}{c}\text { first dorsal } \\
\text { interosseous abductor } \\
\text { digiti minimi }\end{array}$ & finger flexors \\
\hline \multicolumn{3}{|c|}{ Table I'. Clinical Features of Common Cervical Radiculopathy } \\
\hline
\end{tabular}

Some mechanical signs like Spurling's sign which is demonstrated by giving downward pressure with head tilted to the symptomatic side which reproduces pain.

The purpose of this study is to identify the acute events that lead to cervical disc herniation so that necessary preventive action may be taken to prevent disc herniation and thereby prevent loss of man days and valuable health resources.

\section{METHODS}

This retrospective descriptive study includes sixty-eight patients attending the Neurology \& Neurosurgery out door and those who were admitted in the indoor of these departments in Calcutta National Medical College and Hospital with symptoms of cervical radiculopathy. The study period was on and from 01.03.2018 to 28.02.2019.

\section{Inclusion Criteria}

Radicular pain with or without sensory motor signs with MRI evidence of root compression, in the absence of which electrophysiological evidence of root compression and with symptoms onset within the last three months.

\section{Exclusion Criteria}

Patients below the age of 20 years and above the age of 59 years, recurrent attacks, myelopathy spondylotic radiculopathy, other radicular pain, infection, inflammation (Sarcoidosis), infiltration (Malignancy) and other red flags.

A through history was taken from the patients and their family members or any witness particularly searching for acute events in the past forty-eight hours of symptom onset that led to disc herniation. Examination was done to detect root affection by detecting myotomal or dermatomal neurodeficit. Sensory loss by pin prick, cotton wisp, hot \& cold tube, muscle wasting by inspection and measuring tape, weakness by testing muscle power and loss or impairment of deep tendon jerks by hammer. Some mechanical signs are checked like Spurling sign, axial manual traction and shoulder abduction to detect root compression. Investigation were done after only after six weeks of conservative management in the majority of cases. X-ray of cervical spine including AP, Lateral \& Oblique view, MRI of cervical spine in sagittal and axial cuts with T1WI, T2WI, FLAIR sequences were done in all cases. Nerve conduction and EMG studies were done in those cases where MRI evidence of compression was doubtful.

\section{Statistical Analysis}

The data collected in this study was entered in MS Excel and was analyzed using EPI software. Descriptive statistical measures like percentage were applied and the results so derived have been shown in the tables below. No inferential statistics was applied.

\section{RESULTS}

Only those patients who finished the study were included and the total number of patients included in the study was 68 . Patient were in between the ages of 20 to 59 years. Out of 68 patients, $69.1 \%(n=47)$ were male and $30.8 \%(n=21)$ were female. $77.9 \%(n=53)$ of cervical disc prolapse occurred in those below 49 years of age.

\begin{tabular}{|c|c|c|}
\hline Age-Years & Male Percentage (Number) & Female Percentage (Number) \\
\hline $20-29$ & $36.1(17)$ & $28.5(6)$ \\
\hline $30-39$ & $25.5(12)$ & $23.8(5)$ \\
\hline $40-49$ & $19.1(9)$ & $19.04(4)$ \\
\hline $50-59$ & $19.1(9)$ & $28.5(6)$ \\
\hline
\end{tabular}

Table 2. Age and Sex Distribution of Cervical Disc Herniation

\begin{tabular}{|c|c|c|}
\hline Age/Years & Percentage & Number \\
\hline $\mathrm{C}_{7}$ & 69.1 & 47 \\
\hline $\mathrm{C}_{6}$ & 19.1 & 13 \\
\hline $\mathrm{C}_{8}$ & 7.3 & 5 \\
\hline $\mathrm{C}_{5}$ & 4.4 & 3 \\
\hline \multicolumn{2}{|c|}{ Table 3. Root Distribution of Cervical Disc Herniation } \\
\hline \multicolumn{3}{|c}{}
\end{tabular}

\begin{tabular}{|c|c|c|c|c|}
\hline \multirow{2}{*}{ Event } & Percentage of & \multicolumn{4}{|c|}{ No. of Patients } \\
\cline { 3 - 5 } & Patients & T & M & F \\
\cline { 3 - 5 } & 27.9 & 19 & 16 & 3 \\
\hline Road Traffic Accident & 16.1 & 11 & 8 & 3 \\
\hline Lifting heavy objects & 11.7 & 8 & 5 & 3 \\
\hline Violence and assault & 10.3 & 7 & 3 & 4 \\
\hline Fall & 10.3 & 7 & 3 & 4 \\
\hline Repetitive strain & 7.3 & 5 & 4 & 1 \\
\hline Sports and recreation & 4.4 & 3 & 3 & 0 \\
\hline Falling object & 11.7 & 8 & 5 & 3 \\
\hline idiopathic & \multicolumn{5}{|l}{} \\
\hline
\end{tabular}

Table 4. Events Leading to Cervical Disc Herniation 
DISCUSSION

Incidence of cervical radiculopathy occurs at an incidence rate of approximately 85 persons per 100,000 .(2) The most common presentation of herniated cervical disc is radicular pain noticed upon awakening in the morning.(3) The diagnosis of radiculopathy is based on a detailed history taking and a thorough neurological examination. Dermatomal and myotomal symptoms and signs on clinical examination not only confirm radiculopathy but they also help to localize it to a specific root. Sensory loss, wasting and weakness of muscles, and loss or impairment of deep tendon reflexes is diagnostic of cervical disc herniation. Some mechanical test like the Spurling sign where downward pressure is given on a tilted head and is positive when pain appears to the symptomatic side.(4) Axial manual traction test is done by applying $10-15 \mathrm{~kg}$ pulling force to the patients head in supine posture resulting in reduction of pain. Shoulder abduction test is positive when the patient's symptoms are reduced by lifting the arm above the head.(5) Cervical plain film has little value in diagnosis of disc prolapse. MRI scanning of cervical spine can detect root compression by a herniated disc and can help to exclude other causes like infection, inflammation (Sarcoidosis) or infiltration (Malignancy). MRI can be abnormal in the elderly patients due to a high incidence of degeneration. Asymptomatic patients with MRI evidence of cervical disc herniation is seen in nearly $5 \%$ of patient below 40 years of age and in $10 \%$ of cases above 40 years of age. Both lateral and central disc prolapse can occur causing radiculopathy and myelopathy respectively. EMG and NCV studies are helpful to detect myotomal involvement and to exclude brachial plexopathy or peripheral neuropathy and when radiological and clinical features are conflicting. American Association of Neuromuscular and Electro diagnostic Medicine (ANNEM) practice parameters for cervical radiculopathy reports a sensitivity rate of 50-71\% for needle EMG examination and correlation between positive needle EMG and radiology finding are of 65-85\%.(6) EMG testing of paraspinal muscles combining with muscle supplied by root yields best results. Fibrillation and positive waves develop within 1-2 weeks of disc compression. At least one motor and one sensory conduction study in the clinically involved limb is to be done to exclude neuropathy. Common cause of disc herniation in those below 30 years of age is trauma and in those above 40 years of age the most common cause is cervical degeneration. In this study $77.9 \%(n=53)$ of disc prolapse cases occurred in those below 49 years of age, Males are more prone to develop $80 \%$ of cervical disc prolapse. In this study $69.1 \%(n=47)$ were males while $30.8 \%$ $(n=21)$ were female. Age and male distribution of cervical disc herniation as shown in the table 1 were $20-29$ years 36.1 $\%(n=17), 30-39$ years $25.5 \%(n=12), 40-49$ years $19.1 \%$ $(n=9), 50-59$ years $19.1 \%(n=9)$. Age and female distribution of cervical disc herniation were 20-29 years $28.5 \%(n=6), 30$ 39 years $23.8(n=5), 40-49$ years $19.04 \%(n=4)$ and $50-59$ years $28.5(n=6)$.

Commonest cervical radiculopathy is $\mathrm{C} 7$ nerve root involvement in $70 \%$ followed by C- 6 nerve root involvement in $19-25 \%, \mathrm{C}-8$ nerve root involvement in $4-10 \%$ and C-5 nerve involvement in $2 \%$ of patients. ${ }^{(7,8)}$ Our study showed involvement of cervical root was $\mathrm{C} 7$ in $69.1 \%(\mathrm{n}=47), \mathrm{C}-6$ nerve root involvement in $19.1 \%(\mathrm{n}=13), \mathrm{C}-8$ nerve root involvement in $7.3 \%(\mathrm{n}=5)$ and $\mathrm{C}-5$ nerve root involvement in $4.4 \%(\mathrm{~N}=3)$. It proved that $\mathrm{C} 7$ radiculopathy is the commonest root involvement in cervical disc herniation. Auto or motorcycle accidents are the leading cause of spinal cord injuries. $40-50 \%$ of spinal injuries are due to road traffic accidents ${ }^{(9)}$ of which $83 \%$ are male and $17 \%$ are females. Motorized two-wheeler, laborers, bicycle riders and pedestrians are more prone to have road traffic accidents.(10)

The highest number of victims are within 20-29 years of age. In this study $27.9 \%(n=19)$ of patients suffered from cervical disc herniation due to road traffic accidents out of which $84.2 \%(n=16)$ were male. This corroborated with the fact that males are more involved in outdoor activities. Road traffic accidents not only produce spinal cord injuries but also produces radiculopathy depending upon the nature of trauma. Lifting of heavy objects overhead by bending forward without going close to the object or without squatting and standing up can produce cervical disc herniation. Upto $20 \%$ of the person's body weight can be carried with no extra exertion of energy.(11) In this study lifting of heavy objects were the cause of cervical disc herniation in $16.1 \%(n=11)$. Carrying bucket of water, milk; bundle of firewood basket of bricks, soil and road materials are the usual events that correlates with the disc herniation. Violence and assault can be the cause of spinal cord injuries in $15-30 \%$ of cases. In this study violence and assault were the cause of disc herniation in $11.7(n=8)$ of cases. Blow to the neck were made by fist, hand, feet, stick and blunt instruments. They occurred in both indoor and outdoor situations. Like road traffic accidents, violence and assault can produce both radiculopathy with or without spinal cord injuries. Fall was most frequently observed in those above the age of 65 years. Overall fall can cause more then $20-25 \%$ of spinal injuries.(9) Majority of falls occurred in the home during the afternoon or evening. Women are more likely than men to fall and suffer non-fatal injuries.(12) In this study fall was the cause of disc herniation in $10.3 \%(n=7)$ of which $57.1 \%(n=4)$ were female.

Repetitive strain produced by working on computers, cell phone, tablet and other wireless devices too frequently and for too long can produce text neck. The posture of bending the neck forward for prolonged periods can produce stress to the neck structures including cervical disc. Degenerative changes can occur very fast and that can lead to disc prolapse by any usual neck movement. $79 \%$ of the population between the ages of 18 to 44 years have cell phones and they use it all waking hours except 2 hours.(13) In this study repetitive strain produced cervical disc herniation after driving motor cycle for more than 2 hours on a rough road and another cause is reading in bed for long hours. Impact sports and recreational activities like football kabaddi, cricket, diving in shallow water are the cause of spinal injuries in $10-15 \%$ of cases.(9) In this study $7.3 \%(n=5)$ had disc prolapse due to sports and recreational activities. One of these cases suffered after heading a football \& another after landing following catching the cricket ball during fielding. Falling of objects over the neck can produce disc prolapse. Heavy items like bamboo trunks, steel beams, small items like brick, hand tools can fall over the neck and produce disc herniation. In this study $4.4 \%(n=3)$ cases had herniation due to fallen object. All of these cases were male. There are some situations where disc prolapse occurred spontaneously without any known 
cause. In this study $11.7 \%(n=8)$ were idiopathic. In the background of degenerative disc any trivial injury that may not be noticed by individual can produce disc prolapse.

\section{CONCLUSIONS}

There are few studies which have tried to identify the acute events which lead to acute disc herniation although risk factors for degenerative disc disease have been widely studied. This study shows that acute events like road traffic accidents, carrying heavy objects overhead, violence, assault, fall, repetitive strain in neck, sports \& recreation, falling objects are some of the major causes of cervical disc herniation. Doctors, health care providers, and general population have to be made aware of these facts. Applying this knowledge to modify lifestyle can prevent disc prolapse and thereby reduce morbidity and health care expenditure.

\section{ACKNOWLEDGEMENT}

Authors would like to thank Professor Dr. G. P. Mondal, HOD, Department of Neurology, Calcutta National Medical College, and Professor Sumit Deb HOD, Department of Neurosurgery, Calcutta National Medical College for guiding us during this study.

\section{REFERENCES}

[1] Iyer S, Kim HJ. Cervical radiculopathy. Curr Rev Musculoskelet Med 2016;9(3):272-80.

[2] Ament JD, Karnati T, Kulubya E, et al. Treatment of cervical radiculopathy: a review of the evolution and economics. Surg Neurol Int 2018;9:35.
[3] Mayfield FH. Cervical spondylosis: a comparison of the anterior and posterior approaches. Clin Neurosurg 1965;13:181-8.

[4] Spurling RG, Scoville WB. Lateral rupture of cervical intervertebral disc: a common cause of shoulder and arm pain. Surg Gynecol Obstet 1944;78:350-8.

[5] Davidson RL, Dunn EJ, Metzmaker JN. The shoulder abduction in the diagnosis of radicular pain in cervical extradural compressive monoradiculopathies. Spine 1981;6(5):441-6.

[6] American Association of Electrodiagnostic Medicine. Chapter 9: Practice parameter for needle electromyographic evaluation of patients with suspected cervical radiculopathy: summary statement. Muscle Nerve 1999;22:S209-S11.

[7] Marinacci AA. Clinical electromyography. Los Angeles (CA): San Iucas Press 1955.

[8] Levin KH, Maggiano HJ, Wilbourn AJ. Cervical radiculopathies: comparison of surgical and EMG localization of single-root lesions. Neurology 1996;46(4):1022-5.

[9] Zigler JE, Capen DA. Epidemiology of spinal cord injury: a perspective on the problem. In: Levine AM, Eismont FJ, Garffin SR, et al. eds. Spine Trauma. Philadelphia, WB Saunders 1998.

[10] Jha N, Srinivasa DK, Roy G, et al. Injury pattern among road traffic accident cases: a study from south India. Indian Journal Community Medicine 2003;28(2):85-90.

[11] Maloiy GM, Heglund NC, Prager LM, et al. Energetic costs of carrying loads: have African women discovered an economic way? Nature 1986;319(6055):668-9.

[12] 0' Neill TW, Varlow J, Silman AJ, et al. Age and sex influences on fall characteristics. Ann Rheum Dis 1994;53(11):773-5.

[13] Neupane S, Ifthikar Ali UT, Mathew A. Text neck syndrome-systematic review. Imperial Journal of Interdisciplinary Research 2017;3(7):141-8. 